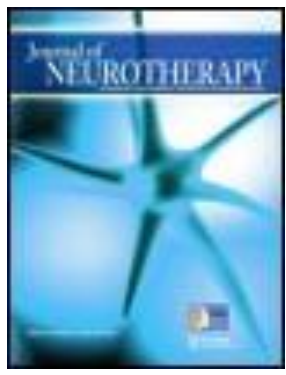

Journal of Neurotherapy: Investigations in Neuromodulation, Neurofeedback and Applied Neuroscience

\title{
Verification Study on the Focused Technology F1000 Software Update
}

\author{
T. Barnes MA ${ }^{a}$, R. Hamilton MEE ${ }^{a}$, S. Reed PhD ${ }^{a} \&$ G. Davis PhD ${ }^{a}$ \\ a Neurotherapy Lab, Department of Rehabilitation Social Work and \\ Addictions , University of North Texas , P.O. Box 310919, Denton, TX, \\ 76203-0919, USA \\ Published online: 17 Oct 2008.
}

To cite this article: T. Barnes MA , R. Hamilton MEE, S. Reed PhD \& G. Davis PhD (2000) Verification Study on the Focused Technology F1000 Software Update, Journal of Neurotherapy: Investigations in Neuromodulation, Neurofeedback and Applied Neuroscience, 4:2, 105-107

To link to this article: http://dx.doi.org/10.1300/J184v04n02_11

\section{PLEASE SCROLL DOWN FOR ARTICLE}

(c) International Society for Neurofeedback and Research (ISNR), all rights reserved. This article (the "Article") may be accessed online from ISNR at no charge. The Article may be viewed online, stored in electronic or physical form, or archived for research, teaching, and private study purposes. The Article may be archived in public libraries or university libraries at the direction of said public library or university library. Any other reproduction of the Article for redistribution, sale, resale, loan, sublicensing, systematic supply, or other distribution, including both physical and electronic reproduction for such purposes, is expressly forbidden. Preparing or reproducing derivative works of this article is expressly forbidden. ISNR makes no representation or warranty as to the accuracy or completeness of any content in the Article. From 1995 to 2013 the Journal of Neurotherapy was the official publication of ISNR (Www. Isnr.org); on April 27, 2016 ISNR acquired the journal from Taylor \& Francis Group, LLC. In 2014, ISNR established its official open-access journal NeuroRegulation (ISSN: 2373-0587; www.neuroregulation.org).

THIS OPEN-ACCESS CONTENT MADE POSSIBLE BY THESE GENEROUS SPONSORS

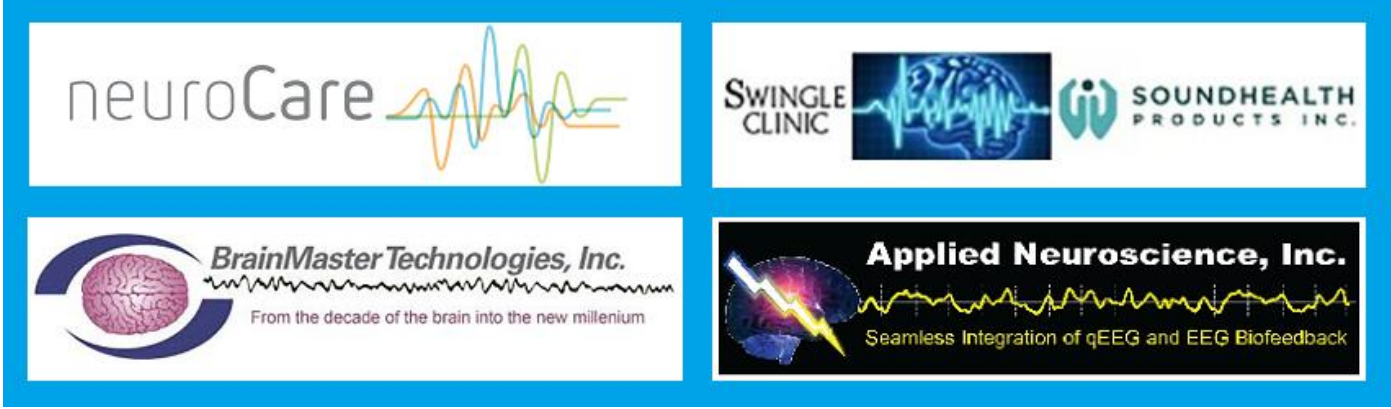




\section{CORRESPONDENCE}

\section{Verification Study on the Focused Technology F1000 Software Update}

Recently the field of neurofeedback has attracted the interest of research scientists. After reviewing the neurofeedback literature and informally interviewing practicing neurologists, Duffy (2000) concluded that practitioners take a number of steps to help the field gain greater acceptance. One step identified by Duffy involved the clarification of some of the technological aspects of neurofeedback equipment. Little work has been done in this area.

To address this void, we have proposed a series of equipment investigations. Pilot work has begun on these studies. Early questions for these studies were generated by our clinical experiences with the equipment in our laboratory. Initially, we attempted to isolate client/therapist/equipment interactions that could account for fluctuations in session-to-session readings we had observed. Our first experimental design called for a comparison of client EEG activity on two identical pieces of equipment (Hamilton \& Barnes, 2000). Our clinic owns two Focused Technology F1000 systems. Since we could compare identical pieces with each other, this was the piece of equipment we chose to begin our pilot work.

Data analysis from a recently completed study (Hamilton, Barnes, Bodenhamer-Davis \& Reed, 2000), demonstrated the existence of a spike anomaly in the F1000 data output. In this study 90 one-minute epochs of data in the 4-7 and the 15-18 Hertz frequency bands were collected. The spike appeared as a thin, barely visible line on the y-axis of the output graphs. This anomaly had a significant impact on the reported means, standard deviations, coeffi-

Journal of Neurotherapy, Vol. 4(2) 2000

Copyright (C) 2000 ISNR. All rights reserved. 
cients of variation and maximum amplitudes (Barnes, Hamilton, BodenhamerDavis \& Reed, 2000). The manufacturer was informed about the spike and a software update was issued to correct the problem.

The present study was conducted to verify that the updated software eliminated the spike. In the verification study 100 one-minute epochs in the 4-7 and the 15-18 Hertz frequency bands were collected. The output graphs were visually inspected. The means, standard deviations, coefficients of variation and maximum amplitudes were analyzed. Results of the analysis confirmed that the spike anomaly was no longer present (see Table 1 ). Table 1 is a cross tabulation of the number of epochs with and without spikes for the two studies.

Means, standard deviations and coefficients of variation are measures used to track client progress over the course of treatment (Lubar, 1991). Invalid output readings due to equipment anomalies impede the therapist's ability to adequately monitor client progress. Also, inaccurate output readings affect the ability of practitioners to demonstrate a correlation between progress in the client's session-to-session EEG activity with other objective and subjective measures of improvement. This type of demonstration is another step that must be routinely taken if the field is to gain wider acceptance.

T. Barnes, $M A$

R. Hamilton, MEE

S. Reed, PhD

G. Davis, $P h D$

Neurotherapy Lab

Department of Rehabilitation

Social Work and Addictions

University of North Texas

P.O. Box 310919

Denton, TX 76203-0919

TABLE 1. Spike Comparison of Old Software (Study 1) and New Update (Study 2)

\begin{tabular}{|l|c|c|c|c|}
\hline & \multicolumn{2}{|c|}{ 4-7 Hz } & \multicolumn{2}{c|}{ 15-18 Hz } \\
\hline & Spike & No Spike & Spike & No Spike \\
\hline Study 1 & 84 & 6 & 46 & 44 \\
\hline Study 2 & 0 & 100 & 0 & 100 \\
\hline
\end{tabular}




\section{REFERENCES}

Barnes, T.A., Hamilton, R.J., Bodenhamer-Davis, E., \& Reed, S. (2000). The effects of an anomaly on data output on the Focused Technology F-1000 biofeedback equipment. Presented at the Texas Women's University Research Symposium, Denton, TX.

Duffy, Frank H. (2000). The state of EEG Biofeedback Therapy (EEG Operant Conditioning) in 2000: An editor's opinion. Clinical Electroencephalography, 31(1), 5-7.

Hamilton, R.J. \& Barnes, T.A. (2000). The investigation of consistency of neurofeedback systems-Part I. Journal of Neurotherapy, 4(1), 63-70.

Hamilton, R.J., Barnes, T.A., Bodenhamer-Davis, E., \& Reed, S. (2000). Neurofeedback equipment investigations. Presented at the Annual meeting of the Association for Applied Psychophysiology and Biofeedback, Denver, CO.

Lubar, J.F. (1991). Discourse on the development of EEG diagnosis and biofeedback treatment for attention deficit/hyperactivity disorders. Applied Psychophysiology and Biofeedback, 16, 201-225. 